\title{
The Occurrence of Glutamic Dehydrogenase in Neurospora and its Apparent Absence in Certain Mutant Strains
}

\author{
By J. R. S. FINCHAM* \\ Botany School, University of Cambridge
}

SUMMARY: A study (Fincham, 1950) of two mutant strains of Neurospora crassa, which probably owed their origin to independent occurrences of mutation at the same locus, showed them to be deficient in their ability to synthesize from ammonia the $\alpha$-amino groups of a wide range of amino-acids. They grew well when any one of a number of different $\alpha$-amino-acids was added to the medium, but would only grow slowly, and after a prolonged lag-phase, in the absence of amino-acid. The corresponding $\mathrm{D}$-amino-acids and $\alpha$-keto-acids were inactive in promoting growth. The mutants were subnormal in their capacity to assimilate ammonium nitrogen. In the present study the L-glutamic acid dehydrogenase activity of dialysed extracts of strains carrying the amination-deficiency mutation, and of a number of other wild-type and mutant strains, was investigated. All strains, with the exception of the amination-deficient strains, yielded an L-glutamic acid dehydrogenase specific for coenzyme II. Extracts of four amination-deficient strains had no detectable glutamic dehydrogenase activity, and did not inhibit the enzyme appreciably when added to wild-type extracts. Glucose-6-phosphate dehydrogenase was present in one extract tested for its presence.

Fincham (1950) described two mutant strains of Neurospora crassa, 32213 and 47305 of the series obtained by Beadle and co-workers, which appeared to have a metabolic block in the reaction normally responsible for the synthesis of $a$-amino groups from ammonia. The mutants, which differ from the wild-type in single Mendelian mutations probably at the same locus in each case, fail to grow on the minimal medium until after a prolonged lag period lasting 4-5 days at $25^{\circ}$ and about 2 days at $35^{\circ}$. On medium supplemented with any one of the biologically occurring $L$ - $\alpha$-amino-acids, with the exceptions of glycine, serine, threonine, histidine, lysine and citrulline, growth begins without this lag, and a growth rate approximating to that of wild-type is achieved on media containing glutamate, aspartate, alanine, ornithine or arginine. The optimum concentration of these amino-acids is about $0.01 \mathrm{~m}$, a very high requirement compared with that of most mutants which require amino-acids. A further property of these mutants is their very slow assimilation of ammonia as compared with wild-type under the same cultural conditions, and their tendency to accumulate ammonia when supplied with nitrate in the medium. It was suggested that the glutamic dehydrogenase system might prove to be absent or subnormal in strains 32213 and 47305 . Evidence is presented in the present paper that this is indeed the case.

\section{MATERIALS AND METHODS}

Strains used. The wild-type strain P4-12 was obtained during breeding work by the author. It carries a spontaneous mutation which is cryptic at $\mathbf{2 5}^{\circ}$, but

* Present address: Botany Dept., University College, Leicester. 
which, at $35^{\circ}$, causes an enhanced requirement for carbohydrate (unpublished observations of S. Emerson and others).

The wild-type strains E5256A and E5297a, derived by Dr Emerson, are known to be free of this mutation, the presence or absence of which has not been determined in the other strains used in this study.

Strain 481-34 carries a mutant gene causing an absence of the usual orange pigmentation in the spores and hyphae, and another mutation resulting in an inability to reduce nitrate to nitrite. This last mutation arose in N. sitophila and was transferred to $N$. crassa by repeated back-crossing from a species hybrid.

Strains 47305A and 32213,Hla were the mutant strains used in the author's original study, and the mutant strains 32213-8 and 47305-12 were derived from the crosses $32213, \mathrm{H1a} \times \mathrm{E} 5256 \mathrm{~A}$, and $47305 \mathrm{~A} \times \mathrm{E} 5297 \mathrm{a}$ respectively. For the sake of brevity, and to distinguish them from wild-type strains and other kinds of mutants, the amination-deficient strains 32213,H1a, 32213-8, 47305A and 47305-12 will be referred to as strains $A_{1}, A_{2}, A_{3}$ and $A_{4}$ respectively.

One culture of $A_{1}$ showed altered properties; amination-deficient strains derived from crosses made with this culture grew rather feebly on all media and were actually inhibited by ammonium salts. The spontaneous mutation responsible was separated from the amination-deficiency mutation by crossing some of the double mutants with a wild-type strain. Strains 88-1 and 88-4 were derived from such a cross: $88-4$ is apparently a normal wild-type, but carries the modifying gene, as shown by a cross between it and a normal amination-deficient strain, while 88-1 does not carry the modifier (the other two spore pairs from ascus 88 gave, respectively, normal and 'inhibited' amination-deficient cultures).

All the other mutant strains used, the properties of which are summarized in the table, were obtained from the Pasadena laboratories by courtesy of Dr G. W. Beadle.

Culture methods. Mycelia for enzyme extractions were grown in Roux bottles each containing $100 \mathrm{ml}$. of the usual Fries No. 3 'minimal' medium (Beadle \& Tatum, 1945) containing ammonium tartrate $(0.5 \%)$, glucose $(1.5 \%)$, biotin ( $5 \mu \mathrm{g} . / 1$.$) and inorganic salts including trace elements, with$ appropriate supplements for the different mutants. A heavy inoculum of 1-2 ml. of a distinctly turbid suspension of conidia in sterile distilled water was used, and cultures were grown without agitation for $60-63 \mathrm{hr}$. at $25^{\circ}$, except where otherwise stated.

Stock cultures were kept on the same minimal medium solidified with agar and with the addition of yeast extract $(0.5 \%, \mathrm{w} / \mathrm{v}$, 'Difco') and malt extract $(2 \%, v / v)$.

\section{Determination of enzyme activity}

In early experiments enzyme activity was followed by determination of ammonia, and, in one experiment, of $\alpha$-ketoglutarate. Ammonia was estimated by the microdiffusion technique of Conway \& Byrne (1933), followed by 
Nesslerization, and $\alpha$-ketoglutarate was estimated by the method described for $\alpha$-keto acids by Sealock (1941). In most experiments, however, enzyme activity was shown by following the reduction and reoxidation of coenzyme II. This was done by measuring the ultra-violet absorption of digests at $340 \mathrm{~m} \mu$. with a 'Uvispek' spectrophotometer.

Preparation of coenzymes. Coenzyme preparations were obtained from horse liver using the methods developed for CoII by LePage \& Mueller (1949). One liver yielded $570 \mathrm{mg}$. of a light brown powder from the first acetone precipitation, and this preparation was shown to contain, by a spectrophotometric assay following the method of LePage (1949), $22 \%$ coenzyme calculated as CoI. Both CoI and CoII were presumed to be present in this preparation, and its behaviour in spectrophotometric experiments, to be described below, suggests that about $50 \%$ of the coenzyme present was CoII. A $0.5 \%$ (neutralized) solution of the preparation at this stage was used in a number of experiments. A further purification of the CoII by chromatography, as described by LePage \& Mueller, yielded $31 \mathrm{mg}$. of a white powder assaying $44 \%$ coenzyme, calculated as CoII. The amount of CoI present, though not determined with certainty, was probably low (see the section on coenzyme specificity). A specimen of CoI, assaying $55 \%$ coenzyme calculated as CoI, was also obtained from the chromatographic column. The CoII preparation was made up as a $\mathbf{0 . 2} \%$ neutralized solution for use, and was kept frozen for up to 10 days.

Enzyme extraction. Mycelium from a single flask was harvested on a large Buchner funnel, washed with $c .700 \mathrm{ml}$. distilled water and c. $80 \mathrm{ml}$. glassdistilled water, sucked fairly dry, pressed lightly between pads of towelling paper, and weighed. The mycelium was then ground with 2 to 4 vol. (usually 3 vol.) of $0.067 \mathrm{M}$ phosphate $\left(\mathrm{Na}_{2} \mathrm{HPO}_{4}-\mathrm{KH}_{2} \mathrm{PO}_{4}\right)$ buffer at $\mathrm{pH} 7 \cdot 25$ or (in a few experiments) $\mathrm{pH} \mathbf{7 \cdot 4}$, with the addition of powdered glass. Grinding was continued vigorously for $10 \mathrm{~min}$. Both the mortar and the buffer were chilled to about $5^{\circ}$ before use, and the mortar was stood in an ice bath during grinding.

In preliminary experiments in which enzyme activity was detected by ammonia estimations, the cream produced by grinding was centrifuged to get rid of cell-wall debris. The milky supernatant was free from large particles but contained many small particles of the order of size of bacteria (presumably mitochondria).

In experiments in which enzyme activity was detected spectrophotometrically, a particle-free extract was produced by filtering the cream produced by grinding through a pad of acid-washed kieselguhr on a small Buchner. At first a pad of 6-8 mm. thickness was used, but it was found difficult to suck such a pad sufficiently dry to avoid a considerable dilution of the enzyme during filtration (such a dilution did occur in the experiments the results of which are shown in Figs. 1, 2 and 3). Later a much thinner pad was found to be satisfactory, and a standard procedure was adopted as follows. Acid-washed kieselguhr (3.4 g.) was suspended in distilled water and poured on to a 2-in. diam. Buchner carrying a Whatman No. 50 filter paper. The pad 
was sucked fairly dry, pressed down to avoid cracks at the edges, washed through with glass-distilled water and dried by attaching to the water aspirator for $\mathbf{3 0} \mathrm{min}$; t this procedure gave a fairly dry pad about $3 \mathrm{~mm}$. thick. The cream produced by grinding mycelium was filtered through this pad by suction. The last 2-3 ml. were retained rather tenaciously by the pad and were usually not collected. The filtrate was opalescent, but appeared free of particles under the $1 / 6$ in. objective of the microscope. About $5 \mathrm{ml}$. of filtrate were dialysed against three changes of $250 \mathrm{ml}$. of the same buffer as used in the extraction, for 30-40 min. each change. During dialysis the external and the internal solutions were kept stirred, and the temperature of the whole was maintained at $\mathbf{0 - 2 ^ { \circ }}$. The dialysed extract was diluted 1/10 for use.

Both the particle-free extracts and extracts containing 'mitochondria' were found to contain a glutamic dehydrogenase (see next section). One attempt was made at a further purification of the enzyme preparation. A protein fraction was precipitated from a dialysed particle-free extract of strain E5297a (wild-type) by the addition, with stirring, of ethanol to a concentration of $40 \%(\mathrm{v} / \mathrm{v})$ at $-5^{\circ}$. The precipitate was centrifuged down and redissolved in $0.067 \mathrm{~m}$ phosphate buffer at $\mathrm{pH} \mathbf{7 \cdot 2 5}$. This preparation showed glutamic dehydrogenase activity (tested for spectrophotometrically), though less than that of the original dialysed extract. A protein fraction precipitating between 40 and $80 \%(\mathrm{v} / \mathrm{v})$ ethanol had no detectable glutamic dehydrogenase activity.

\section{RESULTS}

\section{Enzyme activity measured by ammonia estimation}

Glutamic dehydrogenase activity was first detected in the extracts of wildtype (E5297a) mycelium obtained by grinding and centrifuging. When digests containing $1 \mathrm{ml}$. of E5297a extract buffered at $\mathrm{pH} 7 \cdot 25$, with $\mathrm{NH}_{4} \mathrm{Cl}$ added to give an ammonia concentration of about $4 \mu \mathrm{M} . / \mathrm{ml}$., $0.15 \mathrm{ml}$. of $0.2 \mathrm{M}$ sodium $\alpha$-ketoglutarate, and $0.3 \mathrm{ml}$. of a $1 \%$ neutralized solution of a crude liver nucleotide fraction (assaying $7 \%$ coenzyme, calculated as $\mathrm{CoI}$ ), were incubated for $30 \mathrm{~min}$. at $30^{\circ}$ in evacuated Thunberg tubes, 50-70\% of the ammonia originally present disappeared. In the absence of either the $a$-ketoglutarate or coenzyme there was a small increase in ammonia during the experiment. The reaction proceeded aerobically, but rather more slowly than in evacuated Thunberg tubes. Using ammonia disappearance in the presence of $\alpha$-ketoglutarate as the test for glutamic dehydrogenase activity, the enzyme was detected in extracts of E5297a mycelium grown on minimal medium or on minimal medium supplemented with either $0.02 \mathrm{M}$ DL-alanine or $0.01 \mathrm{~m} \mathrm{L-glutamate.} \mathrm{The} \mathrm{degree} \mathrm{of} \mathrm{activity} \mathrm{shown,} \mathrm{however,} \mathrm{was} \mathrm{not} \mathrm{always}$ consistent from experiment to experiment, and in a few cases no activity was found.

In one experiment, using a dialysed extract of E5297a, disappearance of $\alpha$-ketoglutarate was demonstrated, and the production of glutamate was shown by the appearance of a strong glutamic acid spot in an ascending paper 
chromatogram of the deproteinized reaction mixture, phenol saturated with water being used as the running solvent.

\section{Enzyme activity measured spectrophotometrically}

(a) Experiments using the $\mathrm{CoI}+\mathrm{CoII}$ preparation

In these experiments the cruder preparation mentioned under 'Materials and Methods' (assaying $22 \%$ coenzyme, calculated as CoI) was used. Addition of crude coenzyme solution to dialysed, particle-free extracts (buffered at pH 7.25) of either E5297a or $A_{2}$ led to a rapid reduction of the coenzyme. The increase in absorption observed tended to about $50 \%$ of the theoretical value for complete coenzyme reduction. The coenzyme was not reduced appreciably by boiled extracts.

In four experiments using extracts of E5297a mycelium, grown in one case on minimal medium, in one case on minimal with $0.01 \mathrm{M} \mathrm{L-glutamate,} \mathrm{and} \mathrm{in}$ two cases on minimal with $0.02 \mathrm{M}$ DL-alanine, reduced coenzyme was almost completely reoxidized by the addition of $\alpha$-ketoglutarate and ammonia, each to a final concentration of $0.005 \mathrm{~m}$. When ammonium chloride and $\alpha$-ketoglutarate were present in the digest before the addition of coenzyme, little or no reduction of coenzyme took place. $\alpha$-Ketoglutarate alone had some effect, and the addition of $\alpha$-ketoglutarate was more effective in decreasing the final degree of coenzyme reduction attained than was the addition of an equivalent amount of ammonium chloride. Addition of ammonium chloride to digests containing $\alpha$-ketoglutarate, or of $\alpha$-ketoglutarate to digests containing ammonium chloride, caused almost complete reoxidation of coenzyme. Results of a representative experiment of this type are shown in Fig. 1.

In three experiments using $\mathbf{A}_{2}$ mycelium, grown in one case on minimal with $0.02 \mathrm{M}$ DL-alanine, and in two cases on minimal with $0.01 \mathrm{M} \mathrm{L}$-glutamate, no effect of added ammonia on the degree of coenzyme reduction was found. The results of one of these experiments are shown in Fig. 2. $a$-Ketoglutarate inhibited the reduction somewhat, but this inhibition was independent of ammonia concentration. The $\alpha$-ketoglutarate appeared to have the effect of lowering the concentration of reduced coenzyme with which the system was in equilibrium, since not only did its presence cause the cessation of coenzyme reduction at a lower concentration, but its addition to digests after the coenzyme had become reduced caused a reoxidation to the same concentration of reduced coenzyme as was attained in digests to which $\alpha$-ketoglutarate was added at the start (Figs. 2 and 3 show this phenomenon). This effect of $a$-ketoglutarate is unexplained, but its independence of ammonia indicates that it cannot be due to the presence of glutamic dehydrogenase.

One extract was prepared from mycelium of strain $\mathbf{A}_{2}$ which had been allowed to grow on unsupplemented minimal medium for six days. The results of an experiment with this extract are shown in Fig. 3, and are essentially the same as those obtained using $\mathbf{A}_{2}$ mycelium grown with an amino-acid in the medium. 


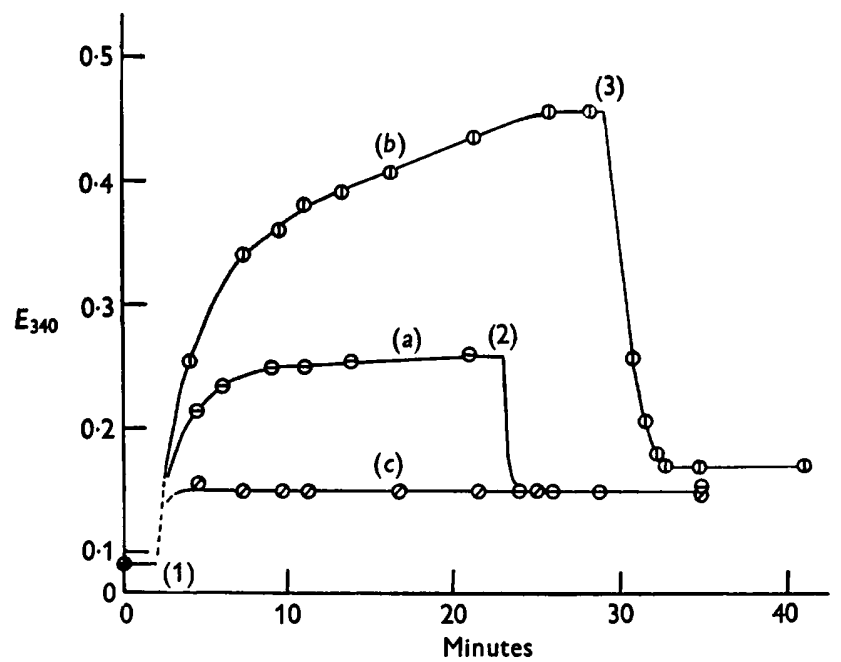

Fig. 1. Coenzyme reduction by extracts of E5297a (wild type) mycelium grown on minimal medium $+0.01 \mathrm{M}-\mathrm{Na}$ L-glutamate. $4.9 \mathrm{~g}$. wet weight of mycelium ground with $12 \mathrm{ml}$. $0.067 \mathrm{~m}$ phosphate buffer at $\mathrm{pH} 7 \cdot 25$, filtered through kieselguhr, dialysed against the same buffer, and diluted with $5 / 7$ vol. of buffer. Spectrophotometer cells (a), (b) and (c) each contain $1.5 \mathrm{ml}$. of diluted extract and receive, respectively, 0.1 ml. 0.1 M.$\mathrm{Na} \alpha$-ketoglutarate $+0.1 \mathrm{ml}$. water, $0.1 \mathrm{ml}$. water $+0.1 \mathrm{ml}$. $0.1 \mathrm{M}-\mathrm{NH}_{4} \mathrm{Cl}$, and $0.1 \mathrm{ml}$. $0.1 \mathrm{M} \alpha$-ketoglutarate $+0.1 \mathrm{ml} .0 \cdot 1 \mathrm{M}-\mathrm{NH}_{4} \mathrm{Cl}$. $0.15 \mathrm{ml}$. of $0.5 \%$ solution of the $\mathrm{CoI}+\mathrm{CoII}$ preparation added to each cell at (1), at (2) $0.1 \mathrm{ml}$. $0.1 \mathrm{M}-\mathrm{NH}_{4} \mathrm{Cl}$ added to (a), and at (3) $0.1 \mathrm{ml} .0 .1 \mathrm{M}-\mathrm{Na} \alpha$-ketoglutarate added to (b). Absorption values are for a vol. of $1.85 \mathrm{ml}$; corrections have been made for dilution and for $\alpha$-ketoglutarate absorption. The absorption of unreduced coenzyme is approximately 0.04. Temperature $22-23^{\circ}$.

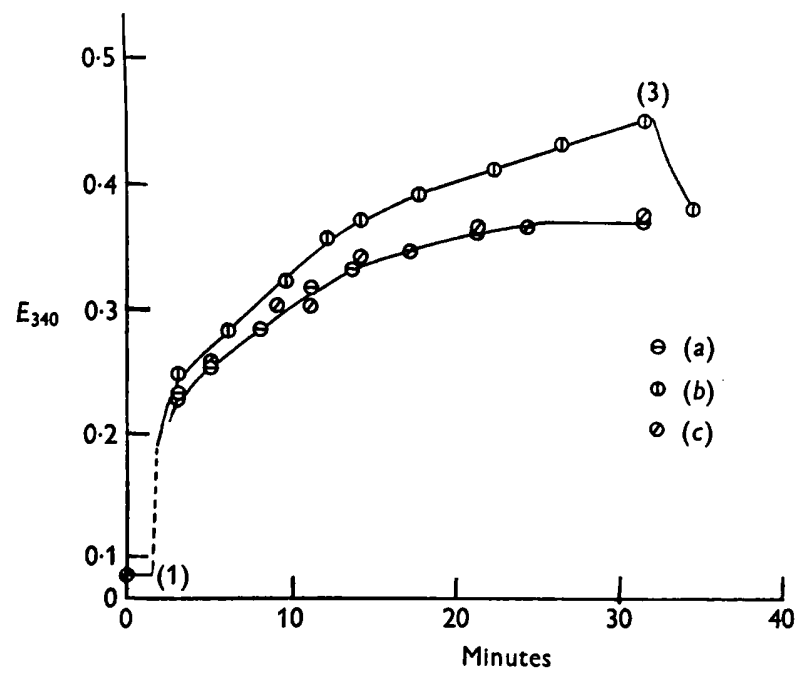

Fig. 2. As for Fig. 1 except that an extract of $A_{2}$ mycelium grown on minimal medium $+0.01 \mathrm{M}-\mathrm{Na}$ L-glutamate used $2.8 \mathrm{~g}$. of mycelium ground with $8 \mathrm{ml}$. buffer, filtered, dialysed and diluted with $3 / 4$ vol. buffer. Temperature $22-23^{\circ}$. 


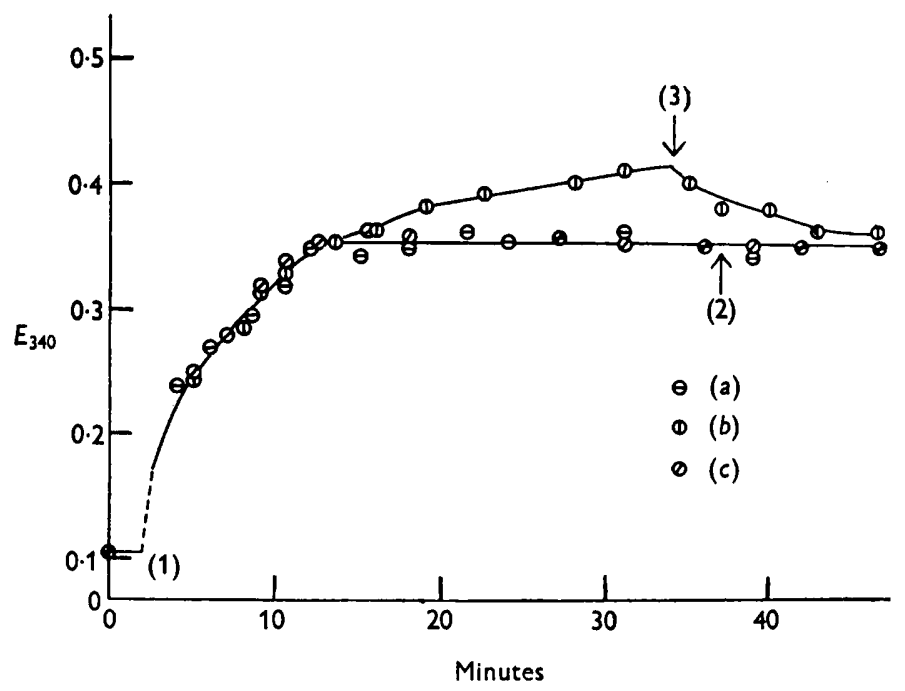

Fig. 3. As for Figs. 1 and 2, except that extract is of $A_{2}$ mycelium grown on minimal medium (unsupplemented) for $142 \mathrm{hr}$. $1.45 \mathrm{~g}$. mycelium ground with $6 \mathrm{ml}$. buffer, filtered through a rather thick $(c .8 \mathrm{~mm}$.) pad of kieselguhr (becoming considerably diluted), dialysed, and used without further dilution. Temperature $22^{\circ}$.

\section{(b) Experiments using the CoII preparation}

Reduction of coenzyme in the absence of glutamate. When the CoII preparation was used instead of the cruder CoI + CoII preparation, the extent to which the coenzyme was reduced by dialysed extracts alone varied from experiment to experiment. The rapidity of reduction of coenzyme in the absence of added glutamate appeared to be a function of the strain used and also of the cultural conditions. Extracts of strains 299, 66702 and E5041 (see table) gave very slow reduction in the absence of glutamate, while other strains all gave more or less higher rates. The amination-deficient strains $\mathbf{A}_{2}$, $\mathbf{A}_{3}$ and $\mathbf{A}_{4}$ all gave rather high control rates of reduction in experiments run at $\mathrm{pH} \mathbf{7 \cdot 2 5}$, although an extract of $\mathbf{A}_{\mathbf{4}}$ reduced coenzyme rather slowly in an experiment at $\mathrm{pH} 7 \cdot 4$ (Fig. 4). An extract of E5297a mycelium grown for $48 \mathrm{hr}$. at $37^{\circ}$ showed a very high rate of reduction of coenzyme even though it was subjected to prolonged dialysis (overnight). No reduction of coenzyme occurred when part of the same extract, after having been heated to $100^{\circ}$ for a few seconds, was used. It is thought probable that the reduction in the absence of glutamate was due to an enzyme, present to different degrees in different extracts, which oxidizes some substrate present in the CoII preparation. No information on the nature of this substrate is available, except that it appears to form part of a CoII-linked system (see below).

Glutamic dehydrogenase activity in different strains. The routine test for glutamic dehydrogenase activity using the CoII preparation was as follows. Two $1 \mathrm{~cm}$. spectrophotometer cells each received $1.5 \mathrm{ml}$. of buffered extract and, respectively, $0.3 \mathrm{ml}$. of $0.5 \mathrm{M}$ monosodium glutamate, and $0.3 \mathrm{ml}$. of 
water. Then $0.1 \mathrm{ml}$. of the $0.2 \%$ solution of the CoII preparation was added to each, and its reduction was followed spectrophotometrically. When the reaction appeared to be approaching equilibrium $0.05 \mathrm{ml}$. of $0.1 \mathrm{M} a$-ketoglutarate was added to each cell, followed, after some minutes, by $0.1 \mathrm{ml}$. of $0.1 \mathrm{~m}$ ammonium chloride. It should be noted that, owing to the fact that $\alpha$-ketoglutarate has itself a significant absorption at $340 \mathrm{~m} \mu$., a correction had to be applied to all readings where $\alpha$-ketoglutarate was present. The size of the correction was determined by measuring the increase in absorption following the addition of 0:01 м $\alpha$-ketoglutarate to the experimental reaction mixtures with water substituted for coenzyme solution.

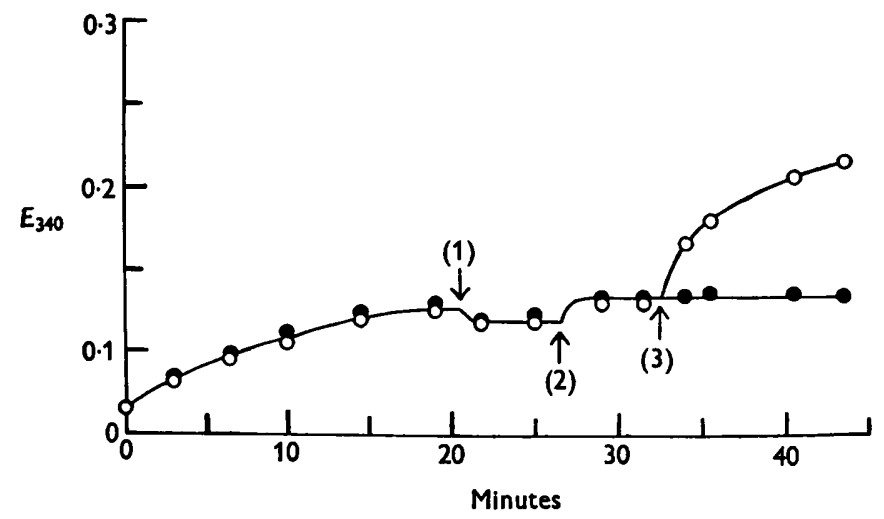

Fig. 4. Experiment on an extract of $A_{2}$ mycelium grown on minimal medium $+0.01 \mathrm{M}-\mathrm{Na}$ L-glutamate. $3.3 \mathrm{~g}$. mycelium ground with $10 \mathrm{ml}$. of 0.067 M phosphate buffer at pH 7.6, filtered through $3 \mathrm{~mm}$. of kieselguhr, dialysed, and diluted with 9 vols. of the same buffer. Spectrophotometer cells (a) (solid circles) and (b) (open circles) each receive $1.5 \mathrm{ml}$. diluted extract plus, respectively, $0.3 \mathrm{ml}$. $0.5 \mathrm{M}-\mathrm{Na} \mathrm{L}$-glutamate and $0.3 \mathrm{ml}$. water. $0.1 \mathrm{ml}$. of $0.2 \%$ solution of CoII preparation added to each at time 0 ,

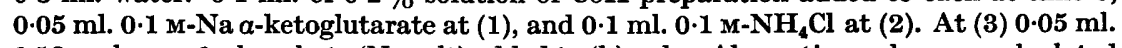
$0.12 \mathrm{M}$ glucose 6-phosphate (Na salt) added to (b) only. Absorption values are calculated for a vol. of $1.9 \mathrm{ml}$., corrections being made for dilution and $a$-ketoglutarate absorption. Absorption of unreduced coenzyme is approximately 0.015 . Temperature $18 \cdot 5^{\circ}$.

Extracts of amination-deficient mutant strains reduced the coenzyme at the same rate, within experimental error, in the presence of added glutamate as in its absence. Some reoxidation of coenzyme followed the addition of $\alpha$-ketoglutarate; this is doubtless the same phenomenon as was observed in the experiments using the cruder coenzyme preparation. The addition of ammonium chloride, however, caused no further reoxidation. Indeed, when allowance was made for the dilution effect of the addition of the ammonium chloride, it appeared in some cases to cause some reversal of the effect of $a$-ketoglutarate (Figs. 4 and 6). It seems clear that there is no evidence for the presence of glutamic dehydrogenase in these extracts. A representative experiment, using an extract of $\mathbf{A}_{\mathbf{4}}$ mycelium, is illustrated in Fig. 4.

Extracts of a considerable variety of other strains, including mutants and several wild-types of different origin, all gave clear evidence of glutamic dehydrogenase activity. The rate of reduction of the CoII preparation was 
always greater in the presence of glutamate than in its absence. The difference was very marked where the rate of reduction in the absence of glutamate was low, and less marked, but definite, where it was higher. Even where the effect of glutamate was rather small owing to the high rate of reduction in its absence, the effect of added ammonium chloride in causing an increased rate of reoxidation was always striking. The results of an experiment where the reduction in the absence of glutamate was intermediate in rate are shown in Fig. 5. The completeness of reoxidation following the addition of $\alpha$-ketoglutarate and ammonium chloride depended on the rate of reduction in the absence of glutamate. Where this rate was low reoxidation was practically complete, while in the case of extracts where it was the highest, reoxidation

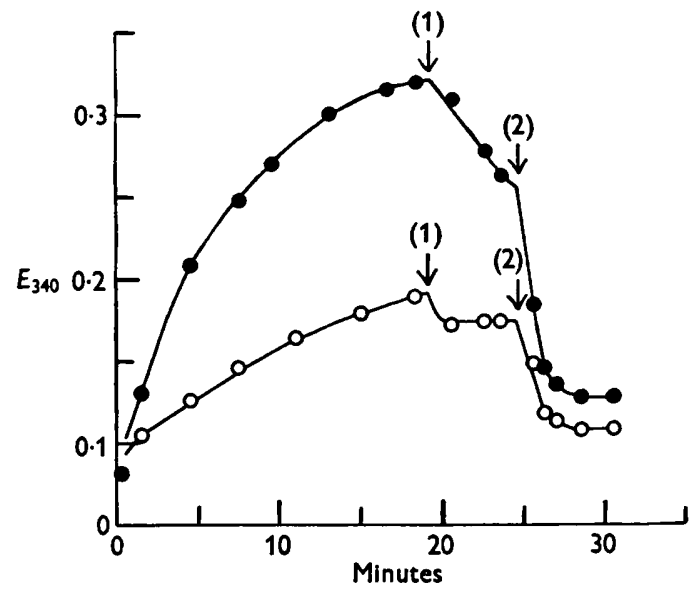

Fig. 5. As for Fig. 4 except that E5297a (wild-type) extract used. 3.5 g. mycelium ground with $10.5 \mathrm{ml}$. buffer at $\mathrm{pH} 7 \cdot 6$, filtered through $3 \mathrm{~mm}$. kieselguhr, dialysed and diluted with 9 vols, of the same buffer. Temperature $18 \cdot 5^{\circ}$.

proceeded only to the extent of about $60-70 \%$ of the coenzyme originally reduced (see, for example, Fig. 6).

In Table 1 the strains tested for enzyme activity using the CoII preparation are listed, together with the conditions under which they were grown. Owing to the lack of constancy in the rates of reduction in the absence of glutamate, only a rough comparison could be made between the degrees of glutamic dehydrogenase activity shown by the different strains. No differences in activity were apparent among the strains in which the enzyme could be demonstrated except in the case of strain 481-56, which yielded an extract with rather low, though still definite, activity. A point of particular interest here, as in the experiments using the cruder coenzyme preparation, is the lack of activity shown by amination-deficient strains grown on minimal medium for long periods. The negative result obtained with $\mathbf{A}_{2}$ mycelium grown on minimal medium at $37^{\circ}$ is regarded with some reserve; it is probable that the mycelium was growing very slowly when harvested, and the lack of opalescence of the extract indicated that the protein content was low. This extract, 
however, reduced coenzyme only very slowly, and even a very low glutamic dehydrogenase activity should have been detectable.

Extracts showing glutamic dehydrogenase activity lost their activity on being heated to $100^{\circ}$ for a few seconds. Activity was, however, little if at all diminished by standing extracts for 2-3 hr. at room temperature, and it seems that some of the precautions observed to keep the extracts cold during preparation could probably have been omitted.

Table 1. Mycelia tested for glutamic dehydrogenase using the CoII preparation

\begin{tabular}{|c|c|c|c|c|}
\hline Strain & $\begin{array}{c}\text { Growth } \\
\text { Requirements }\end{array}$ & $\begin{array}{l}\text { Medium on which } \\
\text { grown-supplements } \\
\text { to minimal }\end{array}$ & $\begin{array}{l}\text { Wet weight } \\
\text { (g.) }\end{array}$ & $\begin{array}{l}\text { Enzyme } \\
\text { activity }\end{array}$ \\
\hline E5297a & - & - & $3 \cdot 8$ & + \\
\hline E5297a & - & - & $\mathbf{3 \cdot 5}$ & $+(4)$ \\
\hline E5297a & 一 & $-(\mathbf{1})$ & $?$ & + \\
\hline $32213-8\left(\mathrm{~A}_{2}\right)$ & $\alpha$-amino $\mathrm{N}$ & $-(2)$ & $\mathbf{0 . 9}$ & - \\
\hline 32213-8 $\left(\mathrm{A}_{2}\right)$ & $\alpha$-amino $\mathbf{N}$ & $-(3)$ & $1 \cdot 1$ & $-(4)$ \\
\hline E5297a & 一 & ) & $3 \cdot 5$ & + \\
\hline P4-12 & - & & $3 \cdot 7$ & $+(4)$ \\
\hline $32213-8\left(A_{2}\right)$ & $\alpha$-amino $\mathbf{N}$ & $0.01 \mathrm{M}-\mathrm{Na}$ & $1 \cdot 8$ & $\rightarrow$ \\
\hline 32213-8 $\left(\mathrm{A}_{2}\right)$ & $a$-amino $\mathbf{N}$ & L-glutamate & $\mathbf{2 \cdot 4}$ & - \\
\hline $47305-12\left(\mathrm{~A}_{4}\right)$ & $\alpha$-amino $\mathbf{N}$ & & $\mathbf{3} \cdot \mathbf{3}$ & $-(4)$ \\
\hline $47305 \mathrm{~A}\left(\mathrm{~A}_{3}\right)$ & $\alpha$-amino $\mathbf{N}$ & $0.01 \mathrm{M}-\mathrm{Na} \mathrm{L}$-glutamate & $2 \cdot 7$ & - \\
\hline 88-1 & - & $+1 \mu \mathrm{g} .110 \mathrm{ml}$. pyridoxin & $\mathbf{3 \cdot 3}$ & + \\
\hline 299 (N. sitophila) & Pyridoxin & & $\mathbf{3} \cdot \mathbf{3}$ & + \\
\hline P4-12 & - & & $3 \cdot 0$ & + \\
\hline $47305-12\left(A_{4}\right)$ & $a$-amino $\mathbf{N}$ & 0.01 M-Na L-glutamate & $\mathbf{3 \cdot 7}$ & - \\
\hline 32213,H1a $\left(\mathbf{A}_{1}\right)$ & $a$-amino $\mathbf{N}$ & + $0.001 \mathrm{~m}$ L-arginine & $2 \cdot 5$ & - \\
\hline $481-56$ & $\begin{array}{l}\text { Nitrite or } \\
\text { ammonium } \mathbf{N}\end{array}$ & pyridoxin & $\mathbf{3 \cdot 2}$ & + \\
\hline 88-4 & - & & $\mathbf{3} \cdot \mathbf{3}$ & + \\
\hline 37803 & Pyridoxin & $\begin{array}{l}\text { Ditto but arginine } \\
0.005 \mathrm{M}\end{array}$ & $4 \cdot 4$ & + \\
\hline E5041 (6) & $\begin{array}{l}\text { Proline, ornithine, } \\
\text { citrulline or } \\
\text { arginine }\end{array}$ & 0.005 м L-arginine $\mathbf{H C l}$ & $\mathbf{3} \cdot \mathbf{3}$ & + \\
\hline $66702(5)$ & $\begin{array}{l}\text { Succinic or a } \\
\text { related acid }\end{array}$ & $0.005 \mathrm{~m}-\mathrm{Na}$ succinate & $1 \cdot 2$ & + \\
\hline
\end{tabular}

Notes: (1) Grown at $37^{\circ}$ for $48 \mathrm{hr}$. Dialysis overnight. (2) Grown at $25^{\circ}$ for $139 \mathrm{hr}$. (3) Grown at $37^{\circ}$ for $90 \mathrm{hr}$. (4) Tested at $\mathrm{pH} \mathrm{7.6} \mathrm{(7.25} \mathrm{in} \mathrm{all} \mathrm{other} \mathrm{cases).} \mathrm{(5)} \mathrm{Lewis} \mathrm{(1948).}$ (6) Srb, Fincham \& Bonner (1950).

Coenzyme specificity. In two experiments using extracts of E5297a (wildtype) mycelium it was found that CoI was not reduced to a detectable extent by extract plus glutamate. In one experiment the CoI preparation obtained as a by-product of the CoII preparation was used, and in the other a specimen, of about $45 \%$ purity, which had been prepared by Williamson's method. The same extracts reduced the CoII preparation rapidly in the presence of glutamate, and slowly in its absence. Thus the Neurospora glutamic dehydrogenase must be specific for CoII. 
In some experiments it was shown that the reduction of coenzyme in the absence of glutamate was completely or almost completely reversed by the glutamic dehydrogenase system (Fig. 5), and in other experiments where the coenzyme added was practically all reduced (Fig. 6), up to $70 \%$ was reoxidized by this system. From this it can be inferred that a system largely or entirely responsible for the reduction of coenzyme in the absence of glutamate also operates with CoII, and that the coenzyme present in the CoII preparation was at least $70 \%$ CoII.

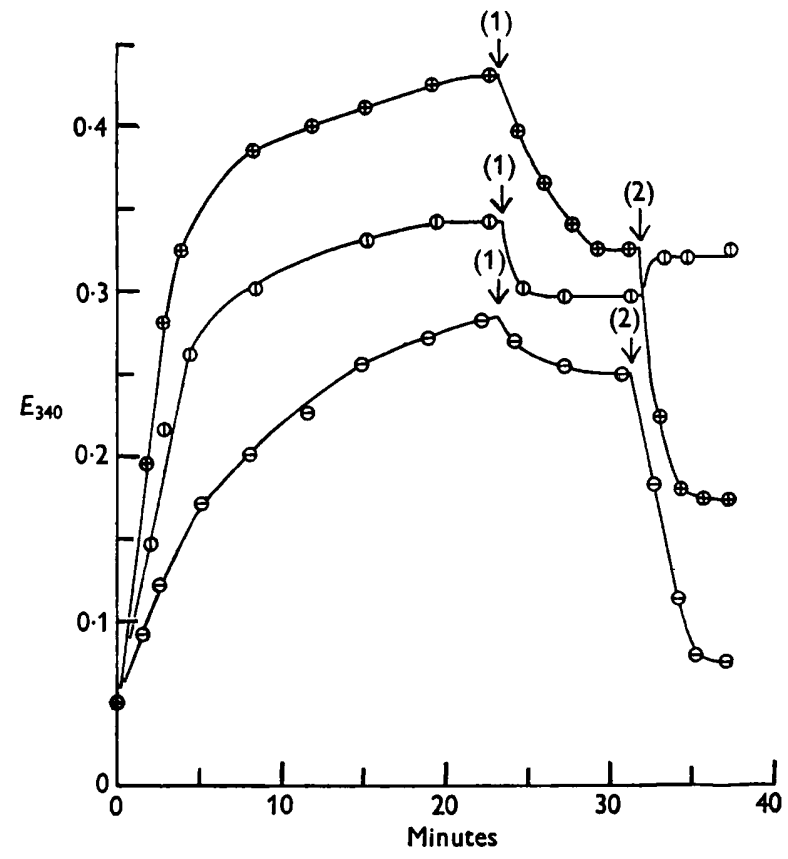

Fig. 6. Experiment on enzyme activity of a mixture of extracts of strains $A_{1}$ and 88-4, grown on the medium given in the table. 3.3 g. of 88-4 mycelium ground with $10 \mathrm{ml}$. $0.067 \mathrm{M}$ phosphate buffer at $\mathrm{pH} \mathrm{7.25}$, filtered through $4 \mathrm{~mm}$. kieselguhr, and dialysed against the same buffer. $2.5 \mathrm{~g}$. of $A_{1}$ ground with $7.5 \mathrm{ml}$. of the same buffer, filtered through $3 \mathrm{~mm}$. kieselguhr, and dialysed similarly. Cell (a) (horizontal lines) contains $1.5 \mathrm{ml}$. of 88-4 extract diluted to $1 / 10$ with buffer. Cell (b) (vertical lines) contains $1.5 \mathrm{ml}$. of $A_{1}$ extract diluted to $1 / 5$ with buffer. Cell (c) (crosses) contains $1.5 \mathrm{ml}$. of a mixture of 1 part undiluted 88-4 extract: 2 parts undiluted $A_{1}$ extract: 7 parts buffer. Each cell receives $0.2 \mathrm{ml}$. $0.5 \mathrm{M}-\mathrm{Na} \mathrm{L}$-glutamate before the addition of $0.1 \mathrm{ml}$. of the $0.2 \%$ solution of the CoII preparation at time 0 . $\alpha$-Ketoglutarate and $\mathrm{NH}_{4} \mathrm{Cl}$ added at (1) and (2) as in Figs. 4 and 5 . Corrections have been made for dilution and $\alpha$-ketoglutarate absorption; readings plotted are for $1.8 \mathrm{ml}$. The increase in absorption observed in (c) $(0 \cdot 38)$ is close to the theoretical value for complete coenzyme reduction $(0 \cdot 37)$. Temperature $19 \cdot 5^{\circ}$.

Activities of mixtures of extracts. It was thought possible that the lack of glutamic dehydrogenase activity shown by extracts of amination-deficient strains might be due to the presence of some inhibiting substance not easily got rid of by dialysis. To test this possibility, extracts of mutants having no activity were added to active extracts of wild-type strains in the expectation 
that any inhibitor present in the former extracts would cause a marked depression in the activity of the latter. The results obtained were not conclusive, in that the rate of coenzyme reduction in the absence of glutamate was increased by the addition of mutant extracts, and reoxidation would, in any case, be expected to be less rapid and complete where this 'background' rate of reduction was higher. However, as will be seen from Fig. 6, any inhibition caused by the mutant extracts must have been relatively slight. Four experiments of this type were carried out with essentially similar results in each case. One of these experiments involved the addition of two parts of the extract of strain $A_{2}$ grown at $37^{\circ}$ (referred to above) to one part of an E5297a extract, the extracts being buffered at $\mathrm{pH} 7 \cdot 4$. In this experiment the 'background' rate of reduction was higher in the digest containing the mixed extracts than in that containing wild-type extract only, but reoxidation was practically complete in both cases and proceeded at the same rate, within experimental error. This experiment, however, was subject to the same reservations concerning the $\mathbf{A}_{2}$ extract as mentioned earlier.

Glucose-6-phosphate dehydrogenase activity. In one extract the presence of this enzyme was demonstrated. The addition of $0.05 \mathrm{ml}$. of a $0.12 \mathrm{M}$ solution of synthetic glucose-6-phosphate (sodium salt) to a digest containing extract of $\mathrm{A}_{4}$ mycelium, buffered at $\mathrm{pH} \mathbf{7 \cdot 6}$, and CoII led to a rapid reduction of the coenzyme (Fig. 4). Further experiments showed that when $0.1 \mathrm{ml}$. of the $0.2 \%$ CoII solution was added to $1.7 \mathrm{ml}$. of the same extract plus $0.05 \mathrm{ml}$. of the glucose-6-phosphate solution, about $85 \%$ of the coenzyme was reduced, equilibrium being reached in 15 min. as compared with $25 \%$ reduction in the same time in control cells with water instead of glucose-6-phosphate.

\section{DISCUSSION}

Though it is unfortunate that a more highly purified sample of CoII was not available, and that the complications due to the reduction of coenzyme in the absence of glutamate and the unexplained effect of $\alpha$-ketoglutarate on this reduction were thus not avoided, the results of the spectrophotometric experiments seem clear. An active glutamic dehydrogenase, specific for CoII, was found in all strains of Neurospora tested except in four known to be carrying a mutation which results in a growth requirement for transferable $\alpha$-amino nitrogen. The enzyme resembles, at least in its coenzyme specificity, the glutamic dehydrogenases of yeast and Escherichia coli (Adler, Günther \& Everett, 1938; Adler et al., 1938).

The results reported in the present paper cannot be taken as final proof that glutamic dehydrogenase is absent from the amination-deficient mutants. It remains possible that the enzyme may be present but is inhibited both in vivo and in vitro by some substance which inhibits the wild-type enzyme little, if at all, in mixtures of wild-type and amination-deficient extracts. Such a situation would imply some difference between the mutant and wild-type enzymes. As an alternative possibility, the inhibitor of glutamic dehydrogenase in the amination-deficient strains might be combined relatively 
indissociably with the enzyme, and not present in the free state to any significant extent in extracts. This condition might be difficult to distinguish from actual absence of enzyme. Yet another possibility, though perhaps rather a remote one, is that a glutamic dehydrogenase is present in the aminationdeficient strains, but that, either because of its own peculiar properties, or because of some peculiarity in the nature or organization of other cell constituents, it cannot be obtained in active form by the extraction methods used in this work. Thus, though it seems probable that glutamic dehydrogenase is not produced by the amination-deficient strains, further work with a more highly purified system would be necessary to exclude alternative interpretations.

The work on the biochemical genetics of Neurospora has led to the conception (see, for example, Bonner, 1946) that single gene mutations have their effect through affecting the specificities of single enzymes. Although this hypothesis appears plausible, little good evidence in its favour has yet been forthcoming. Two cases in which an enzyme appeared to be affected by a gene mutation have turned out to be less simple than at first appeared. The first case concerned a pantothenic acid-requiring strain the intact mycelium of which could not be shown to possess the enzyme responsible for linking $\beta$-alanine and pantoyl lactone. Wagner (1949) has shown that the enzyme activity is readily obtained in in vitro preparations of the mutant. In this case, if the one gene-one enzyme relationship holds, there is no clue as to which enzyme is primarily affected. The second case, reported by Mitchell \& Lein (1948), was one in which a strain requiring tryptophan for growth gave no tryptophan desmolase activity in extracts. According to a more recent report, however (Gordon \& Mitchell, 1950), the mutant contains a tryptophan desmolase which is inhibited by certain substances normally present in the cell. The case reported in the present paper appears, at least on the surface, to be one in which the one gene-one enzyme hypothesis in its simplest form may hold. It is thought that further investigation of this case might cast some light on the gene-enzyme relationship by providing answers to such questions as, for instance, whether the mutants produce a protein similar to glutamic dehydrogenase, but lacking its specificity for coenzyme or glutamate.

The biochemical implications of this study seem rather more clear. The apparent absence of glutamic dehydrogenase in extracts of mutants having a general requirement for $\alpha$-amino groups reinforces the suggestion, made in the author's previous report (1950), that, in Neurospora, the $a$-amino groups of all the amino-acids which support growth of the mutants are derived, at least to a very large extent, from ammonia via the glutamic dehydrogenase system. Such an origin for the $\alpha$-amino groups of such a variety of amino-acids would require the existence of a wide range of transaminases such as has been recently shown to occur in bacteria (Feldman \& Gunsalus, 1950) and animal tissues (Cammarata \& Cohen, 1950).

It was previously shown by the author (1950) that the amination-deficient mutants are capable of assimilating inorganic nitrogen, even though their 
capacity to do so is impaired in comparison with wild-type. The failure to detect any glutamic dehydrogenase in mutant mycelium even when it had, after a prolonged incubation period, started to grow on minimal medium, suggests that this uptake of ammonia by the amination-deficient strains is due to some accessory amination mechanism which becomes especially developed under these circumstances.

The author is indebted to Dr C. S. Hanes for the use of the spectrophotometer, to Mr B. C. Loughman for glucose 6-phosphate and to Mr E. J. Morgan, of the Biochemical Laboratory, for CoI. The charcoals used in the coenzyme preparation were obtained through the kindness of Professor Goddard of the University of Pennsylvania, to whom the author is also indebted for a number of useful suggestions. Dr D. G. Catcheside and Dr E. F. Gale have given helpful advice on the presentation of the data.

\section{REFERENCES}

Adler, E., Günther, G. \& Everetr, J. E. (1938). Über den enzymatischen Abbau und Aufbau der Glutaminsäure. IV. In Hefe. Hoppe-Seyl. Z. 255, 27.

Adler, E., Hellström, V., Günther, G. \& Euler, v. H. (1938). Über den enzymatischen Abbau und Aufbau der Glutaminsäure. III. In Bacterium coli. Hoppe-Seyl. Z. 255, 14.

Beadle, G. W. \& Tatum, E. L. (1945). Neurospora. II. Methods of producing and detecting mutations concerned with nutritional requirements. Amer. J. Bot. $32,678$.

Bonner, D. M. (1946). Biochemical mutations in Neurospora. Cold Spr. Harb. Sym. quant. Biol. 11, 14.

Cammarata, P. S. \& Cohen, P. P. (1950). The scope of the transamination reaction in animal tissues. J. biol. Chem. 187, 439 .

Conway, E. J. \& Byrne, A. (1933). An absorption apparatus for the microdetermination of certain volatile substances. I. The micro-determination of ammonia. Biochem. J. 27, 419.

Feldman, L. I. \& Gunsalus, I. C. (1950). The occurrance of a wide variety of transaminases in bacteria. J. biol. Chem. 187, 821.

Fincham, J. R. S. (1950). Mutant strains of Neurospora deficient in aminating ability. J. biol. Chem. 182, 61 .

Gordon, M. \& Mrtchell, H. K. (1950). Tryptophane desmolase in Neurospora. Genetics, 35, 110.

Le Page, G. A. (1949). In Umbreit, W. W., Burris, R. H. \& Stauffer, J. F.; Manometric Techniques and Tissue Metabolism. Minneapolis: Burgess Publishing Co.

Le Page, G. A. \& Mueller, G. C. (1949). Preparation of T.P.N. J. biol. Chem. $180,975$.

LEwIS, R. W. (1948). Mutants of Neurospora requiring succinic acid or a biochemically related acid for growth. Amer. J. Bot. 35, 292.

Mrtchell, H. K. \& Lein, J. (1948). A Neurospora mutant deficient in the enzymatic synthesis of tryptophan. J. biol. Chem. 175, 481 .

SEALOCK, R. R. (1941). The determination of amino-acids of the dextro or unnatural configuration. Science, 94, 73.

Srb, A. M., Fincham, J. R. S. \& Bonner, D. M. (1950). Evidence from gene mutations in Neurospora for close metabolic relationships among ornithine, proline and $a$-amino $\delta$-hydroxy valeric acid. Amer. J. Bot. 37, 533.

WAGNER, R. P. (1949). The in vitro synthesis of pantothenic acid by pantothenicless and wild type Neurospora. Proc. nat. Acad. Sci., Wash. 35, 185.

(Received 20 November 1950) 